the Cephalopoda, deals with the initial chamber of the Nautiloidea, especially in the genus Orthoceras. Dr. Richard Johann Schubert and Dr. Lukas Waagen give an account of the Lower Silurian phyllopod genus Ribeiria, and establish a new genus, Ribeirella, for the species $R$. Sharpei, Barr. The remains of a male sheep's skull Ovis Mannhardi) from the neighbourhood of Eggenburg are described by F. Toula, and carefully compared with recent and fossil forms; the paper is illustrated by a plate showing three views reproduced by photography and by three text figures. Dr. W, Hammer gives an account of the minute structure of porphyrite and diorite rocks from Ultenthal, giving six excellent photographic reproductions of microscopic sections. Dr. O. Able, in a memoir of some $5^{\circ}$ pages, treats of the Tertiary marls and sandstones of the Tulln basin from both stratigraphical and physical stand points, and comes to the conclusion that they begin with the Lower Oligocene and continue in unbroken series to the base of the Oncophora sands (Middle Miocene). Four sections across the valley are given to show the folding of the beds. Dr. Karl Alphons Penecke, in a paper of a dozen pages, describes a number of Upper Devonian corals obtained by Dr. Franz Scaffer from Hadschin, Antitaurus, during his journey in Asia Minor. Three new species are named. These corals are finely reproduced by photography on four double plates. In the last paper of this part Dr. W. Petrascheck describes some Inocerami from the Chalk of Bohemia and Saxony, giving the names Ino. hercynieus and Ino. crassus to two new species. This troublesome genus needs a thorough revision, and it is hoped that ere long someone will be found to undertake this useful piece of work. at least for the Cretaceous species.

\section{ATMOSPHERIC ABSORPTION AND EMISSION OF THE EXTREME ULTRA-VIOLET RADI- ATIONS.}

N O. I4I3 of the "Smithsonian Contributions to Knowledge " is devoted to a paper by Dr. Victor Schumann, of Leipzig, in which he minutely describes the apparatus used and the results obtained by him in spectroscopically determining the absorption and emission of air and its constituents for light of wave-lengths between $25^{\circ} \mu \mu$ and Ioo $\mu \mu$. He obtained the photographic spectra of $\mathrm{N}, \mathrm{O}$, $\mathrm{CO}_{2}, \mathrm{CO}$, aqueous vapour and hydrogen by means of an ingeniously constructed spectrosoope, from which he could exhaust all the gas except that on which he was experimenting, and this he introduced, in layers of definite thick nesses, after repeated purification. All the optical parts of the apparatus were made of white fluorspar, which is the most transparent substance, for these extreme ultra-violet rays, yet known.

Dr. Schumann found that nitrogen is very transparent even beyond $162 \mu \mu$, but absorbs particular wave-lengths very energetically; the emission spectrum extends beyond I62 $\mu \mu$. Oxygen absotbs the radiations near to $185 \mu \mu$ in a series of clearly resolved groups of lines, fourteen in number, complete absorption taking place beyond the most refrangible group of the series. This absorption is believed to be the cause of the atmosphere's opacity for radiations more refrangible than $185 \mu \mu$. The absorption spectrum of $\mathrm{CO}_{2}$ is similar in appearance to that of oxygen, but extends to much shorter wave-lengths; the persistent presence of bands due to carbon monoxide-which is one of the greatest difficulties Dr. Schumann has had to contend with in all his experiments, because their photographic action is exceedingly energetic and they extend far beyond $162 \mu \mu$ has prevented the exact determination of the more refrangible limit of the $\mathrm{CO}_{2}$ spectrum, which is exceedingly rich in lines. Carbon monoxide absorbs the more refrangible rays a little less than $\mathrm{CO}_{2}$. The results of the experiments on the spectrum of aqueous vapour are rather uncertain owing to the formation of dew, but it chiefly consists of the hydrogen spectrum, the strong oxygen maximum at $185 \mu \mu$, and a number of other lines the origin of which is at present unknown. The results, however, lead to the conclusion that a regular dissociation of the water vapour, accompanied by a simultaneous recombination, takes place. The results obtained with hydrogen are exceedingly interesting, and are discussed in extenso by $\mathrm{Dr}$. Schumann. They show that hydrogen is intensely transparent, but the limit of transparency is not yet definitely determined. Twenty-fold enlargements of the hydrogen spectrum-having a total length of I. 4 metres-are reproduced in the paper, and show about I500 lines between $185 \mu \mu$ and $127 \mu \mu$. Dr. Schumann states, however, that this latter value is rather uncertain, and is probably not the inferior limit of the true hydrogen spectrum as photographed by him. He also believes that between ${ }^{8} 8_{5} \mu \mu$ and $369.9 \mu \mu$ the hydrogen spectrum is continuous.

\section{UNIVERSITY AND EDUCATIONAL INTELLIGENCE.}

MR. S. A. F. WHITE, demonstrator in natural philosophy in King's College, London, since 1895, has been appointed professor of mathematics in succession to Prof. Hudson.

DR. W. A. OsBorne has been appointed to the professorship of physiology and histology in the University of Melbourne in succession to Dr. C. J. Martin, F.R.S., now director of the Lister Institute.

THE Technical Education Board of the London County Council has arranged for two courses of free lectures for teachers to be given at the Horniman Museum, London Road, Forest Hill, S.E., on Saturday mornings from January 23 to May 26. Prof. Geddes will lecture on the natural history of plants, and a course of lectures on the natural history of man will be given by Prof. Alfred C. Haddon, F.R.S.

The annual meeting of the Association of Public School Science Masters will be held at Westminster School on Saturday, January 16 , beginning at 1.45 p.m. Prof. W. A. Tilden, F.R.S., president of the Association, will be in the chair. Mr. R. E. Thwaites will read a paper on the possibility of fusing the mathematical and science teaching of public schools; and a discussion on science in the certificate examination will be opened by Mr. W. A. Shenstone, F.R.S., and Mr. M. D. Hill, who will deal with the chemical and biological parts of the examination respectively. Mr. O. $\mathrm{H}$. Latter will read a paper on nature-study.

THE eleventh annual general meeting of the Association of Technical Institutions will be held on Friday, January 29, at the Leathersellers' Hall, London, E.C., the president, Sir John Wolfe Barry, K.C.B., F.R.S., in the chair. Sir John E. Gorst, K.C., M.P., has consented to be nominated president of the association for the year 1904. Among other subjects to be brought before the meeting are :--Report as to the constitution of the advisory committee for the leather irades industries, in connection with the City and Guilds of London Institute, Prof. Wertheimer; the differences between the curricula and methods of staffing in British and American higher technical institutions, Dr. Walmsley; the consultative committee of the Board of Education and teachers' registration council, Principal Wells and Dr. Sumpner; and leaving certificates for secondary schools, Prof. Wertheimer and Principal Gannon.

AN interesting essay by Dr. Walther Schoenichen on "The Evolution Theory in Schools" (Die Abstammungslehre im Unterrichte der Schule) has been published by the firm of Teubner (Leipzig and Berlin). The author shows that school instruction in botany and zoology has already passed through several phases-encyclopædic, systematic, analytic, and ethological-and maintains that the time has come for making it frankly evolutionary. This is necessary for scientific reasons and desirable for educational reasons, and, according to the author, it is also quite feasible. He argues that it will be useful ethically and will not endanger religion. The essay is wise and temperate, and many of the practical hints are very suggestive, e.g. the diagrams contrasting the multiplication of the hare and the elephant the evolution of the kohl-rabi cabbage, and the origin of light-coloured from dark-coloured mice by selection. 